\title{
Childhood and adolescent forms of Huntington's disease
}

\author{
JACK OLIVER AND KENNETH DEWHURST
}

From Borocourt Hospital, Reading, and Littlemore Hospital, Oxford

Huntington's original description of involuntary movements and dementia affecting certain families referred only to adults, although a juvenile or adolescent form (thought by some to be a separate clinical entity) has for long been associated with his name, despite attempts at reclassificaton. Myrianthopoulos (1966), for example, has suggested 'striatocortical degeneration of children in families with Huntington's chorea'; whereas Barrows and Cooper (1963) prefer to call this form 'Huntington's disease of childhood', which, though less specific, does at least get rid of the misleading word 'chorea', often overshadowed by rigidity in the younger age groups. Indeed, the neurological syndrome in babies may be regarded as spasticity, quadriplegia, or birth injury; and in older children it may be mistaken for subnormality, Wilson's disease, Friedreich's ataxia, Hallervorden-Spatz syndrome, or post-encephalitic Parkinsonism, as the typical choreic-athetoid movements of the adult form are often absent. We regard the term Huntington's disease of childhood as being too restrictive, as it precludes cases presenting in the second decade.

This childhood variation of Huntington's disease has been reviewed by Bittenbender and Quadfasel (1962), Jervis (1963), and Brion and Comoy (1965). The latter boldly state that the syndrome of infantile Huntington's disease is so clearly defined as to allow an accurate diagnosis to be made even in the absence of a positive family history. The high proportion of mistaken diagnoses suggests that Brion and Comoy take a too-optimistic view.

After developing normally, the child becomes clumsy, ataxic, dysarthric, and mentally backward. Epileptiform seizures often develop. Jervis (1963) found that 14 out of 21 infantile cases developed rigidity, and eight had chorea similar to that in adults. The extrapyramidal type of rigidity is slowly progressive, with plastic hypertonia, cogwheeling and limitation of passive movements leading to rigidity of all four limbs, and, occasionally, hyperextension of the head with neck stiffness.

We believe that the childhood and adolescent forms of Huntington's disease are not as uncommon as is generally thought. Previous studies of 25 pedigrees in depth (Oliver, 1969; Dewhurst, Oliver, and McKnight, 1969) have revealed five new cases and one probable case of childhood or adolescent Huntington's disease which are described here.

The high infantile death rate in our Huntington families is suggestive of undiagnosed cases of Huntington's disease in early childhood. The ensuing case reports illustrate the diagnostic difficulties: they are also the basis of a hypothesis as to its aetiology in relation to the adult form.

\section{CASE REPORTS}

CASE 1 A girl aged $3 \frac{1}{2}$, having passed the normal milestones, became ataxic and incontinent. She failed to learn satisfactorily, and was eventually sent to a special school where she was found to have hypertonia and athetosis.

When she was 6 , she developed both grand and petit mal seizures which became progressively worse. The family background was poor. The girl's father was afflicted with Huntington's disease and showed markedly psychopathic behaviour. The mother went out to work and this child had been 'cared for' by her 10-year-old sister. As the latter began to neglect her own schooling, her sister's admission became necessary.

The child showed violent temper tantrums, dysarthria, and increasing hypertonia of all muscle groups. She became afraid of walking for fear of falling, and muscular rigidity limited flexion of her knees.

At this stage, she was referred to a specialist in physical medicine who diagnosed Friedreich's ataxia-the mother having firmly denied any family history of Huntington's disease. Seizures increased in frequency; spasticity became more marked, and flexion deformities developed. Choreic jerkings became apparent, though partly masked by spasticity. Now aged 11 , she occasionally gets vasomotor disturbances with chilling, pallor, and violent muscular spasms.

Special investigations Serial EEGs showed reduced alpha $(8 \mathrm{c} / \mathrm{sec}$ intermittent) with abnormal 4 to $6 \mathrm{c} / \mathrm{sec}$ activity demonstrated. Atypical spike-and-wave bursts were frequent. Serial records over one year showed an increase in paroxysmal activity. 
CASE 2 A girl, having passed the normal milestones, was found between the ages of 6 to 12 to be unable to make any progress at an elementary school. Her gait was noticeably ataxic and Romberg's sign was positive. She developed irregular, involuntary jerking movements of her head and her speech became indistinct. At the age of 12 she was certified as being ineducable and transferred to a mental deficiency institution with a diagnosis of Friedreich's ataxia.

On investigating her family history, it was found that she belonged to the fourth generation of a Huntington's family described by Pleydell (1955) (Northants pedigree nine). The diagnosis was, therefore, amended to Huntington's disease of childhood. She died aged 14. There was no necropsy.

CASE 3 The patient, a female born in 1935, is a member of the third generation of Northants pedigree 17 (Oliver, 1969). This pedigree is characterized by a long prodromal phase, the principal symptom of which is intellectual dullness. She was described by two relatives as 'seeming all right as a young child', but became 'dull and slow' during her later schooling from the ages of 8 to 13 years. About one year later she developed twitching movements of the limbs with facial tics and grimaces thought to be due to Sydenham's chorea.

Between the ages of 25 and 30 she developed an anxiety state with occasional outbursts of hysterical behaviour. Social deterioration progressed with apathy, suspiciousness accompanied by aggression, and occasional outright brutality to young children.

At the age of 31 years she was found to be dysarthric, demented, and prone to epileptic seizures. She became irritable, restless, suspicious, and developed a paranoid attitude. She tended to confabulate, and showed evidence of impaired judgement and insight. There are now (1969) unequivocal choreiform jerks of the muscles of the face, neck, and shoulders. She has developed a heavy, broadbased, lordotic, and ponderous gait. She has recently been dismissed from the local choir on account of loss of vocal control resulting in squeakiness.

The house was grossly untidy and she began to hoard rubbish. This, plus episodes of petty pilfering and selfneglect, illustrate the progressive dementia.

Special investigations An electrocephalogram in March 1968 showed excess generalized slow wave activity.

Impression Juvenile Huntington's chorea beginning insidiously in childhood was the impression given. Having previously been a normal child, she began to show dullness between the ages of 8 to 13 years. Thus, the onset of early dementia (regarded as subnormality) antedated a florid adolescent episode of typical chorea wrongly diagnosed as Sydenham's chorea. The chance of two such uncommon conditions coinciding is so rare as to be discounted.

CASE 4 A girl, whose father died from Huntington's disease, progressed satisfactorily until the age of 4 when her speech became indistinct and monosyllabic.

Two months later she became incontinent and there was further speech deterioration. She was vicious, distractible, quarrelsome, and over-active. Her comprehension was poor, she did not obey simple commands, and was only able to name simple objects.

At the age of 4 years 9 months, she was certified as an imbecile and admitted to a subnormality hospital. Two years after admission, when she was $6 \frac{1}{2}$, her general mental development was that of a child of 3 .

By the age of 10, she had shown slight educational and social progress, but her speech remained slurred and indistinct. She had occasional outbursts of violence and head-banging. Terman Merrill IQ tests showed progressive deterioration from the age of 11 in parallel with the slow clinical deterioration. By the age of $15 \frac{3}{4}$ her IQ was 30.

At 18, prominent clinical features included stereotyped side-to-side rocking mannerisms and constant headnodding with frequent temper tantrums.

Two years later, aged 20 , in addition to the foregoing features, she showed, for the first time, slight jerky movements of her limbs which subsequently increased in frequency. At 22 years, her gait became broad-based and lordotic.

During the next 12 months she became more unsteady and there was a marked increase in choreic jerks necessitating more prolonged spells of bed rest. She had vasomotor attacks with episodes of fainting. She died, aged 25, of pneumonia. There was no necropsy.

Impression Childhood Huntington's disease with early dementia, dysarthria and relatively late onset of ataxia and chorea was the impression given.

CASE 5 This boy was the fourth of seven children born to a farm labourer, and brother of the previous patient. The home environment was poor, and when he was 2 . years old, his father (after a long period of brutality towards the children) was certified as insane due to Huntington's disease. When the patient was aged 7 , the children were taken into the care of the local authority after their mother had been consorting with soldiers.

The boy soon proved unmanageable at his foster home and was transferred to a special school where his IQ was found to be 79. After another transfer to a school for maladjusted boys, he became so violent and unmanageable that he was moved, at the age of 11 , to the juvenile wing of a mental hospital. He remained there for 18 months and his outbursts of violence continued unabated. At interview he constantly fidgeted, but there was no evidence of chorea. It was noted, however, that he became dysarthric during an emotional outburst.

At the age of 17 he was certified as 'feeble-minded', and admitted to a subnormality hospital. As he frequently absconded he was transferred to a special hospital where he was described as 'an arrogant homosexual, violent and destructive'. He became depressed and expressed suicidal notions. The diagnosis was changed to acute schizophrenia and he was given a course of electroplexy. Afterwards he developed mannerisms of the head and neck which were regarded as confirming the diagnosis of catatonic schizophrenia and deep insulin coma therapy was prescribed.

In 1966 he was transferred to another subnormality hospital where he was found to be in a state of advanced dementia with severe choreo-athetoid movements and 
marked dysphagia. He is now totally aphasic, emotionally labile, aggressive, and destructive. He has little comprehension, but can still communicate his needs and feelings by gestures and grunts.

Impression In this case, as in cases 2, 3, and 4, organic dementia was not distinguished from subnormality in spite of declining serial IQ examinations. Like cases 1 and 4, the grossly stressful family environment must have contributed to the symptomatology in respect of the personality disorders shown by these children.

This patient illustrates the vague borderland between juvenile and adolescent forms of the disease. At the age of $12 \frac{1}{2}$ he showed signs of early dementia, occasional dysarthria, severe personality disorder, and, although it was known that he came from a choreic family, the final diagnosis was not reached until he was about 18 years old.

CASE 6 A boy born at full term by forceps delivery was the eldest of three children of a 27-year-old epileptic father. His mother (case 3), aged 32, and maternal grandfather are confirmed cases of Huntington's disease. The child developed normally until the age of $4 \frac{1}{2}$ when he was referred to a consultant paediatrician because of anaemia, a cardiac murmur, and some slight delay in reaching the milestones. When he was 5 years old he was found to be on the 25th percentile of normal in weight and the 10th percentile of normal in height for his age.

He was restless, over-active and his behaviour was, in general, immature. He occasionally urinated, and persistently masturbated, in public. He stole food from others and reacted poorly to discipline. His speech was thick and slurred.

He could not do up his braces, showed general distractibility, together with a lack of appreciation of right/left discrimination and an inability to copy patterns.

He was referred to a psychiatrist who found signs and symptoms of emotional disturbance. There were no psychotic features or early signs of schizophrenia. At the age of 6 a neurologist found 'possible slight choreic movements' on protrusion of the tongue, and splaying of the left fingers in 'a slightly athetoid position' when the arms were outstretched. He concluded, however, that no definite neurological abnormalities could be detected.

Special investigations An electrocephalogram in March 1968 (aged 6 years 8 months) showed generalized excess slow wave activity. Psychological assessment (1966) revealed an IQ of 90 .

Impression This child is probably a case of Huntington's disease, although the severe emotional and behavioural disorders may have been brought on by cruelty and neglect.

\section{DISCUSSION}

Several factors contribute to the diagnostic problems of juvenile and adolescent Huntington's disease. First, there is the difficulty of obtaining an accurate history as many families are notoriously adept at concealing the illness. All our cases had a positive family history and were obtained as a result of investigating pedigrees in depth. Secondly, the diagnostic label of subnormality is often attached to these children who are then admitted to long-stay institutions. Thirdly, the earliest signs of Huntington's disease in adults are difficult to elicit: they are even more vague and indefinable in the child. We agree with Pleydell (1955) that dyslalia is one of the earliest signs, although it is often overlooked in children, particularly when present only in association with an emotional disturbance. Fourthly, rigidity rather than chorea is a predominant diagnostic feature during the first decade. According to Jervis (1963) only $1 \%$ of cases of Huntington's disease occur in children under 13 years. We suggest that this figure is too low, as in our series $12 \%$ of 102 cases of Huntington's disease showed some degree of Parkinsonism. Bell (1934) found that $10.4 \%$ of 460 cases of Huntington's disease occurred under the age of 20 years, and $18.7 \%$ presented in patients under 25 years. According to Bittenbender and Quadfasel (1962) rigidity occurs 13 to 14 years earlier than the onset of the more typical signs and symptoms of Huntington's disease. Markham and Knox (1965) regard between $1 \%$ to $6 \%$ of all cases of Huntington's disease as showing some degree of rigidity.

Seizures more commonly occur in childhood and adolescent forms of Huntington's disease. Indeed, Byers and Dodge (1967) found that two-thirds, and Markham and Knox (1965) found that half, of their patients had fits.

In a previous paper, Oliver (1969) has shown the high death rate of children under the age of 11 from choreic families. He found that at least 17 children out of 210 died in the first decade. Their deaths were vaguely described as being due to 'spinal paralysis', 'backwardness', 'sickly and weak', 'paralysed', etc. Furthermore, there is a high infant mortality rate in choreic families hitherto ascribed to birth injury, quadriplegia, and spasticity. We believe that a number of these early deaths may, in fact, have been due to unrecognized Huntington's disease. Members of Huntington families also tend to have a high incidence of abortions and miscarriages.

It should, however, be borne in mind that all these children from choreic families (whether carrying the specific gene or not) are the victims of a disruptive, disorganized, and often brutal home environment. We found evidence of several brutal attacks on children, including one case of infanticide.

Juvenile and adolescent forms of Huntington's disease have a similar histological involvement as those of adults (Jervis, 1963), although Denny-Brown (1962) has postulated that rigidity is due to involvement of the globus pallidum. The latter view has been rejected by several French workers, including Tridon, Laxenaire, Weber, and Labourgade (1964), Brion 
and Comoy (1965), and Delmas-Marsalet, Bourgeois, Vital, and Fontanges (1968) who recognize lesions of the putamen and caudate nucleus as being responsible for the rigidity seen in the childhood forms. They regard lesions of the globus pallidum as causing contractions, athetoid movements, and hemiballismus. We agree with Brion and Comoy (1965) and Delmas-Marsalet et al. (1968) who state that the childhood and adolescent varieties of Huntington's disease occur more frequently than is generally thought. And we can confirm also the observation of Bittenbender and Quadfasel (1962), Perrine and Goodman (1966), Brion and Comoy (1965), and Delmas-Marsalet et al. (1968) that the rigid form of the disease tends to run in certain families.

The controversial problem as to whether there is, in fact, a progressive worsening of hereditary diseases in succeeding generations should now be considered. This question of 'anticipation', with the disease occurring at an earlier age in the offspring than in the parent, has a particular relevance to juvenile forms. Penrose (1948) postulated that early cases of Huntington's disease may be due to the effect of an allelic gene from the unaffected parent causing early signs and symptoms.

Byers and Dodge (1967) do not agree with this theory. They have described two cases of childhood Huntington's disease in half siblings whose common father was affected. Their findings would render Penrose's explanation unlikely though not impossible. Brion and Comoy (1965) and Delmas-Marsalet et al. (1968) also oppose Penrose's view, and, instead, they favour the theory of anticipation. Furthermore, they have reported another instance of Huntington's disease in two half-brothers from different mothers. The illness ran a similar course in both half siblings. We suggest that this hypothesis of anticipation may, in fact, be influenced to some extent by the artefact of more diligent observation. When a choreic family history is positive, then the earliest signs and symptoms are more diligently sought, and hence children tend to be diagnosed much earlier than their parents, as is illustrated in cases 4 and 5 . It would seem, therefore, that the theory of anticipation is virtually impossible to test because of the chronological difficulties of the same observer undertaking a detailed study of the development of the disease through three or more generations.

Finally, we venture to proffer a hypothesis to explain the rigid type of Huntington's disease of childhood. In our opinion, there is a temporal and an anatomico-pathological continuum between the age of onset of the disease and the degree of rigidity. Younger patients would, on the whole, tend to be more rigid, and this correlation between age of onset and degree of rigidity is directly related to the phylogenetic development of the whole extrapyramidal system, modified, to some extent, by specific familial characteristics of the disease.

\section{SUMMARY}

A study of Huntington's pedigrees in depth has revealed five new cases and one probable case of juvenile or adolescent forms of the disease. We believe that these early clinical manifestations are not as uncommon as is generally supposed, as a high proportion of patients tend to be misdiagnosed. Most commonly such children are regarded as being subnormal; other differential diagnoses include Wilson's disease, Friedreich's ataxia, HallervordenSpatz syndrome, or post-encephalitic Parkinsonism.

Although the majority of juvenile and adolescent forms of Huntington's disease present with some degree of rigidity rather than the typical choreoathetosis of the adult variety, the anatomicopathological involvement is the same in both.

We do not share Penrose's theory that early cases of Huntington's disease are due to the effect of an allelic gene from the unaffected partner. Nor do we view with favour the hypothesis of anticipation, which is virtually impossible to test owing to observer error.

We suggest that there is a temporal and an anatomico-pathological continuum between the ageof onset of the disease and the degree of rigidity. It may well be related to the phylogenetic development of the extrapyramidal system, modified, to some extent, by specific familial characteristics of the disease.

\section{REFERENCES}

Barrows, H. S., and Cooper, W. C. (1963). Rigidity as a disease form of Huntington's disease. Bull. Los. Angel. neurol. Soc., 28, 144-147.

Bell, J. (1934). Huntington's chorea. Treas. hum. Inherit., 4, 1-67.

Bittenbender, J. B., and Qaudfasel, F. A. (1962). Rigid and akinet ic forms of Huntington's chorea. Arch. Neurol. (Chic.), 7, 275-288.

Brion, S., and Comoy, C. (1965). Rigidité et chorée de Huntington. La forme infantile de la maladie de Huntington. Rev. Neurol., 112, 183-199.

Byers, R. K., and Dodge, J. A. (1967). Huntington's chorea in children. Neurology (Minneap.), 17, 587-596.

Delmas-Marsalet, P., Bourgeois, M., Vital, C., and Fontanges, X. (1968). Formes rigides de la maladie de Huntington. Rev. Neurol., 118, 273-283.

Denny-Brown, D. (1962). The Basal Ganglia and their Relation to Disorders of Movement. Oxford University Press: London.

Dewhurst, K., Oliver, J., and McKnight, A. L. (1969). Familial characteristics of Huntington's disease. In press.

Jervis, G. A. (1963). Huntington's chorea in childhood. Arch. Neurol. (Chic.), 9, 244-257.

Markham, C. G., and Knox, J. W. (1965). Observations on Huntington's chorea in childhood. J. Pediat., 67, 46-57.

Myrianthopoulos, N. C. (1966). Huntington's chorea. J. med. Genet., 3, 298-314.

Oliver, J. E. (1969). Huntington's chorea in Northamptonshire. Brit. J. Psychiat., in press. 
Penrose, L. S. (1948). The problem of anticipation in pedigrees of dystrophia myotonica. Ann. Eugen. (Lond.), 14, 126-132.

Perrine, G. A., and Goodman, R. M. (1966). A family study of Huntington's chorea with unusual manifestations. Ann. intern. Med., 64, 570-574.
Pleydell, M. J. (1955). Huntington's chorea in Northamptonshire. Brit. med. J. 2, 889.

Tridon, P., Laxenaire, M., Weber, M., and Labourgade, F. (1964). Forme infantile de chorée de Huntington. Rev. Neurol., 110, 531-535. 